\title{
Do experimentally induced ipsilateral testicular torsion, vas deferens obstruction, intra-abdominal testis or venous obstruction damage the contralateral testis through a common mechanism?
}

\author{
F. ANDIRAN, D.H. OKUR*, A. KILINÇ†, G. GEDIKOḠLUł, K. KILINÇ† and F.C. TANYEL \\ Departments of Paediatric Surgery, *Paediatric Haematology, †Biochemistry and \$Pathology, Faculty of Medicine, Hacettepe \\ University, Ankara, Turkey
}

Objective To evaluate if various conditions affecting the ipsilateral testis which also damage the contralateral testis share a common pathway for their effects.

Materials and methods The study comprised five groups of 10 adult rats which underwent surgery to produce (on their left sides); group 1, a sham operation (control); group 2, testicular torsion; group 3, vas deferens obstruction; group 4 , an intra-abdominal testis; and group 5, venous obstruction. The ipsilateral and contralateral testes were harvested 4 weeks after surgery. The relative proportions of haploid cells, the mean seminiferous tubular diameter (MSTD), mean testicular biopsy scores (MTBS), and lactate and hypoxanthine levels were determined and compared.

Results The proportions of haploid cells in the ipsilateral and the contralateral testes of groups $2-5$ were significantly lower than those of the corresponding testes of the control group. The MSTD and MTBS of the ipsilateral testes in groups $2-5$ were also significantly lower than the ipsilateral testes of controls and the contralateral testes within the same groups. While the
MSTD and MTBS of the contralateral testes of groups 1 and 5 were not significantly different, those of the contralateral testes of groups 2-4 were significantly less than that of group 1. The lactic acid and hypoxanthine levels of the ipsilateral and contralateral testes were significantly increased in groups 2 and 3. While only the hypoxanthine level of group 5 increased significantly, both variables were not significantly different between the ipsilateral testes of groups 1 and 4 .

Conclusions These four treatments damaged both the ipsilateral and contralateral testes. As the lactic acid and hypoxanthine levels within the contralateral testis were greater than in the controls, testicular torsion and vas deferens obstruction seem to share a common pathway (which may be a reflex decrease in contralateral testicular blood flow) for their effects on the contralateral testis.

Keywords Spermatic cord torsion, vas deferens obstruction, cryptorchidism, testicular venous obstruction, varicocele, DNA flow cytometry

\section{Introduction}

The contralateral testis also deteriorates if an ipsilateral testis is damaged for various reasons, including incarcerated inguinal hernia, maldescent, varicocele, torsion, vas deferens obstruction or tumour [1-9]. Although a mechanism of deterioration for each of the pathologies has been proposed individually [2,10-15] a common pathway for contralateral testicular deterioration seems more feasible. The most popular theory, commonly proposed to explain the contralateral testicular damage, has been an autoimmune response [12]. However, the deterioration of the contralateral testis within $24 \mathrm{~h}$ of

Accepted for publication 20 September 1999 spermatic cord torsion even in the absence of ipsilateral testis and epididymis makes the role of autoimmunity obscure [1,10,14-18].

Experimental models of unilateral testicular torsion and maldescent have resulted in decreased blood flow and an increase in the biochemical indicators of tissue hypoxia within the contralateral testes. Of the latter, lactate and hypoxanthine are reliable indicators of tissue hypoxia and their elevation in the absence of hereditary metabolic diseases, intoxication, increased exercise and anaerobic metabolism, and hepatic and renal failure indicates depressed tissue perfusion $[19,20]$. The increase in biochemical indicators of tissue hypoxia and contralateral testicular damage can be prevented by chemical sympathectomy [21-23]. These studies have suggested 
that the contralateral testis may be damaged by a reflex decrease in blood flow from the activated sympathetic system [13,21-26].

Therefore, an experimental study was conducted to evaluate whether various conditions that are known to damage both ipsilateral and contralateral testes share a common pathway affecting the contralateral testis. DNA histograms, histology and biochemical indicators of tissue hypoxia of the testes were determined and compared after inducing torsion, vas deferens obstruction, abdominal testis or venous obstruction in the ipsilateral sides.

\section{Materials and methods}

The study comprised 50 adult male albino rats housed in a temperature- and light-dark cycle controlled environment with free access to water and rat chow. The animals were randomly allocated into one of five equal experimental groups undergoing surgery performed under ether anaesthesia using a sterile technique; left-sided abdominoscrotal incisions were used. In group 1 (control) the left testis was exposed and a 4/0 atraumatic silk suture placed through the tunica albuginea. In group 2 (torsion) the left testis was exposed, twisted $720^{\circ}$ clockwise and fixed by a 4/0 atraumatic silk suture through the tunica albuginea and soft tissue. In group 3 the vas deferens was obstructed; the left vas deferens was exposed and ligated by a 4/0 silk suture $2 \mathrm{~cm}$ from the epididymis. In group 4 (abdominal testis) the left testis was elevated and fixed cranial to the internal inguinal ring, with no twisting. In group 5 (venous obstruction) the main branch of the left spermatic vein was exposed and ligated completely by a 4/0 silk suture $1 \mathrm{~cm}$ before joining to the left renal vein, as described in an experimental model of varicocele in the rat [7]. Venous dilatation was confirmed during the follow-up.

At the end of 4 weeks, both testes were harvested and divided into three equal pieces; two pieces of each testis were sealed in containers and stored in a deep freeze, being later used to determine the DNA content, and the levels of lactic acid and hypoxanthine, respectively. The third piece of testis was fixed in Bouin's solution for histological evaluation.

The pieces for DNA analysis were warmed to $20-25^{\circ} \mathrm{C}$ and cut into $1 \mathrm{~mm}$ cubes in $1 \mathrm{~mL}$ of $0.5 \%$ pepsin. After dispersing the tissues in $0.25 \mathrm{mg} / \mathrm{mL}$ collagenase (Sigma Chemical Co., St Louis, MO) and 5 mL RPMI 1640 tissueculture medium containing $10 \%$ fetal calf serum, the tissues were fixed in $70 \%$ ethanol. They were then treated with ribonuclease and pepsin before being stained with propidium iodide (Sigma Chemical Co.) for flow cytometry. The DNA content of the dispersed testicular cells was measured by flow cytometry (Coulter Epics XL, Coulter
Corp., USA). The degree of fluorescence is directly proportional to the amount of stain absorbed and so directly related to the DNA content of each cell. Populations of cells having similar amounts of DNA are represented by discrete peaks on a histogram. The histograms were analysed with the curve-integration routines provided by the appropriate Coulter software. The relative proportions of haploid $(\mathrm{N})$, diploid $(2 \mathrm{~N})$ and tetraploid $(4 \mathrm{~N})$ cells were calculated from the area under each peak in the DNA histogram, and the percentages of haploid cells used as an index of spermatogenesis [27].

The pieces fixed in Bouin's solution were embedded in paraffin blocks, sections cut at $6 \mu \mathrm{m}$ thickness, and stained with haematoxylin and eosin. Testicular biopsies were examined in random order by the same pathologist unaware of the groups. The 50 most circular tubules were identified in each testicular biopsy section and their diameters measured using a $\times 40$ objective and an ocular micrometer. The mean seminiferous tubular diameter (MSTD) was determined for each testis. Germinal epithelial maturity was graded using a modified Johnsen testicular biopsy score, using a $\times 40$ objective; 50 tubules were evaluated and each tubule was given a score from 1 to 10. The mean testicular biopsy score (MTBS) was determined for each testis [3].

The concentrations of lactic acid in tissues were determined enzymatically using lactate dehydrogenase and NAD; lithium lactate was used as the lactate standard. The absorbencies of blank standards and deproteinization supernatants, prepared and studied under identical conditions, were measured at $340 \mathrm{~nm}$. By comparing the absorbency of samples with lactate standards, tissue lactate levels were calculated per gram of wet tissue [24].

To measure hypoxanthine levels in tissues, $0.4 \mathrm{~mL}$ of deproteinization supernatant was neutralized with $0.5 \mathrm{~mL} \mathrm{~K}_{3} \mathrm{PO}_{4}(0.7 \mathrm{~mol} / \mathrm{L})$. The tubes were kept at $0^{\circ} \mathrm{C}$ for $5 \mathrm{~min}$ and precipitated $\mathrm{KClO}_{4}$ removed by centrifugation. A $0.5-\mathrm{mL}$ aliquot of clear supernatant was mixed with $2 \mathrm{~mL} 0.1 \mathrm{~mol} / \mathrm{L}$ Tris-HCl buffer (pH 7.4) containing $3 \mathrm{~mol} / \mathrm{L}$ EDTA. The absorbency of the resulting mixture at $37^{\circ} \mathrm{C}$ was read at $293 \mathrm{~nm}$. Then, 0.04 units of xanthine oxidase was added in $20 \mathrm{~mL}$ (the absorbency contributed by the enzyme was 0.200). Tubes were incubated at $37^{\circ} \mathrm{C}$ for $10 \mathrm{~min}$ and absorbencies again read at $293 \mathrm{~nm}$. The conversion of hypoxanthine to uric acid was completed in 5-6 min and the absorbency changes used to calculate the hypoxanthine concentration, taking the molar absorptivity of uric acid as 12200. Hypoxanthine concentrations in tissues were also determined using hypoxanthine as the standard, prepared and studied under the same conditions; the two methods gave identical results. The hypoxanthine levels in tissues were also expressed per gram of wet tissue [24]. 
All results are presented as the mean (sd); the proportions of haploid cells, MTBS and MSTD values were compared among groups using a one-way anova, and the paired $t$-test used to compare each group. Lactic acid and hypoxanthine values were compared among the groups using the Kruskall-Wallis test, and the Mann-Whitney U-test in each group. In all tests, $P<0.05$ was considered to indicate statistically significant differences.

\section{Results}

The proportions of haploid cells in the ipsilateral and contralateral testes of group 1 were not significantly different (Table 1), but the proportions in the contralateral testes were significantly higher than those of the ipsilateral testes within the same groups in groups $2-5$ $(P<0.05)$. The proportion in the ipsilateral testes of group 1 was significantly higher than that in the ipsilateral testes of all of the other groups $(P<0.05)$. The ipsilateral testes of groups 2 and 4 had the lowest proportion of haploid cells. While the proportions in the ipsilateral testes of groups 3 and 4 were significantly less than that of group $5(P<0.05)$, the value in group 3 was greater than that of group $4(P<0.05)$. The proportions in the contralateral testes of groups 2-5 were significantly lower than in group $1(P<0.05)$. The proportion in the contralateral testes of group 2 was significantly higher than that of groups 3 and 4 , and was significantly less than that of group $5(P<0.05)$. The proportion in the contralateral testes of group 3 was significantly less than in groups 4 and $5(P<0.05)$. That in the contralateral testes of group 4 was also significantly less than in group $5(P<0.05$; Table 1$)$.

While the MSTD of the ipsilateral and contralateral testes of group 1 did not differ significantly, those of the ipsilateral testes of groups $2-5$ were significantly lower than in the corresponding contralateral testes $(P<0.05)$. The MSTD of ipsilateral testes of groups 2-5 were significantly less than that of group $1(P<0.05)$, with the values increasing significantly from group 2 to group 5 $(P<0.05)$. The MSTD of the contralateral testes of groups 1 and 5 were not significantly different but those in groups 2-4 were significantly less than in group 1 $(P<0.05)$; those in groups 2 and 3 were not significantly different, but the values of both groups were significantly less than the values of groups 4 and $5(P<0.05)$, with that in group 4 less than in group $5(P<0.05$; Table 1$)$.

The MTBS of the ipsilateral and contralateral testes of group 1 did not differ significantly $(P>0.05)$, but those in the ipsilateral testis in groups $2-5$ were significantly lower than in the contralateral testes of the same group $(P<0.05)$. The MTBS of the ipsilateral testes of groups $2-$ 5 was significantly less than that of group $1(P<0.05)$ and the values increased significantly from group 2 to 5 $(P<0.05)$. The MTBS of the contralateral testes of groups 1 and 5 were not significantly different but the contralateral MTBS of groups 2-4 were significantly less than that of group $1 \quad(P<0.05)$. While the contralateral MTBS of groups 2 and 3 were significantly less than that of group $5(P<0.05)$, that in group 4 was no different from that in group 5; the values in groups 2 and 3 were significantly less than those of groups 4 and 5 $(P<0.05$; Table 1$)$.

Table 1 The percentages of haploid cells, MSTD, MTBS and metabolite levels in the ipsilateral and contralateral testes

\begin{tabular}{|c|c|c|c|c|c|}
\hline \multirow[b]{2}{*}{ Mean (SD) variable } & \multicolumn{5}{|l|}{ Groups } \\
\hline & 1 & 2 & 3 & 4 & 5 \\
\hline \multicolumn{6}{|l|}{$\%$ haploid cells } \\
\hline Contralateral & $70.5(4.5)$ & $55.2(5.7)$ & $46.7(6.1)$ & $52.2(4.7)$ & $59.9(5.2)$ \\
\hline Ipsilateral & $69.4(3.4)$ & $2.7(1.5)$ & $18.4(4.4)$ & $2.4(1.6)$ & $55.3(3.9)$ \\
\hline \multicolumn{6}{|l|}{ MSTD } \\
\hline Contralateral & $288.3(31.31)$ & $202.5(28.32)$ & $187.4(28.39)$ & $257.8(30.16)$ & $276.4(29.14)$ \\
\hline Ipsilateral & $286.5(30.02)$ & $12.08(26.89)$ & $130.6(29.70)$ & $231.1(30.06)$ & $251.9(29.47)$ \\
\hline \multicolumn{6}{|l|}{ MTBS } \\
\hline Contralateral & $10.0(0.0)$ & $7.74(0.92$ & $6.96(0.85)$ & $9.16(0.99)$ & $9.60(0.85)$ \\
\hline Ipsilateral & $10.0(0.0)$ & $1.42(0.88)$ & $5.00(0.98)$ & $6.64(1.08)$ & $9.14(0.88)$ \\
\hline \multicolumn{6}{|c|}{ Lactic acid ( $\mu \mathrm{mol} / \mathrm{g}$ wet tissue) } \\
\hline Contralateral & $1.64(0.39)$ & $2.20(0.60)$ & $2.15(0.21)$ & $1.86(0.32)$ & $1.91(0.35$ \\
\hline Ipsilateral & $1.90(0.26)$ & $2.83(0.59)$ & $3.13(0.40)$ & $2.07(0.38)$ & $1.93(0.38)$ \\
\hline \multicolumn{6}{|c|}{ Hypoxanthine (nmol/g wet tissue) } \\
\hline Contralateral & $34.64(6.31)$ & $43.76(9.15)$ & $48.48(8.13)$ & $37.20(10.55)$ & $36.08(8.46)$ \\
\hline Ipsilateral & $36.64(7.60)$ & $60.32(13.00)$ & $62.88(9.31)$ & $39.92(8.26)$ & $48.56(10.30)$ \\
\hline
\end{tabular}


The lactic acid and hypoxanthine contents of the ipsilateral and contralateral testes were not significantly different in groups 1 and 4 (Table 1), and while the hypoxanthine levels were significantly higher in the ipsilateral testes of group $5(P<0.05)$, the lactic acid levels were no different. Both lactic acid and hypoxanthine levels were significantly higher in the ipsilateral than in the contralateral testes in groups 2 and $3(P<0.05)$. Both levels of the ipsilateral testes of groups 2 and 4 were significantly higher than in group $1(P<0.05)$. Although the ipsilateral lactic acid levels of groups 1 and 5 were not significantly different, the hypoxanthine level was significantly higher in group 5 $(P<0.05)$. Both the ipsilateral lactic acid and hypoxanthine level of group 4 were no different than that in group 1. The levels of both metabolites in the ipsilateral testes of groups 2 and 3, and of groups 4 and 5 were not significantly different, but the levels in groups 2 and 3 were significantly higher than in groups 4 and $5 \quad(P<0.05)$. The levels of both metabolites in the contralateral testes of groups 2 and 3 were significantly higher than those of group 1 $(P<0.05)$ but the contralateral levels were not significantly different among groups 1,4 and 5 . The contralateral levels in group 2 were not significantly different from those in groups 3-5, but the levels within the contralateral testes of group 3 were significantly higher than in group $4(P<0.05)$. The contralateral lactic acid levels of groups 3 and 5 were not significantly different, but the hypoxanthine level of group 3 was significantly higher than that of group 5 $(P<0.05$; Table 1$)$.

\section{Discussion}

Several variables, including the MSTD, MTBS and DNA flow cytometry, have been used to evaluate the status of the testis. Among these, DNA flow cytometry is accepted to be better $[27,28]$ and the MSTD reportedly more sensitive than MTBS [16,23]. DNA flow cytometry showed lower haploid cell proportions in both the ipsilateral and contralateral testes of all the groups than in the controls, with the lowest values among the ipsilateral testes. The MSTD and MTBS of the ipsilateral testes of the experimental groups were less than in the controls and also less in the contralateral testes than those of the controls in groups 3-5. The only group with no significant difference in contralateral testicular MSTD and MTBS values compared with controls was group 5. Although the contralateral testes of rats in group 5 did not seem to be affected (as assessed by MSTD and MTBS), DNA flow cytometric analysis revealed damage to the contralateral testes.
Pathologies that damage the ipsilateral testis are known to also damage the contralateral testis and result in diminished fertility [1-9]. The present study also confirmed that torsion, vas deferens obstruction, abdominal testis and venous obstruction damaged both testes; furthermore, it confirmed that DNA flow cytometry detected testicular damage which was undetected by the MSTD and MTBS.

Unilateral testicular torsion has been reported previously to decrease noradrenaline content and blood flow, and increase the indicators of tissue hypoxia in the contralateral testis $[13,18,21,24]$. The increase in these indicators within the contralateral testis did not require the presence of the ipsilateral testis and even the epididymis. Torsion of only the remaining ipsilateral spermatic cord after epididymo-orchidectomy increased the level of the indicators within the contralateral testis $[16,17,28]$. Chemical sympathectomy by $6-\mathrm{OH}$ dopamine before torsion prevented the increase in tissue hypoxia and spared the histology of the contralateral testis $[21,22,27]$. These findings suggested that the blood flow to the contralateral testis was decreased through a reflex mechanism when the ipsilateral testis and/or vas deferens was under stress. The present study also confirmed that ipsilateral testicular torsion, which results in deterioration of both ipsilateral and contralateral testes, also resulted in increased lactic acid and hypoxanthine levels within both testes, with the increase being more prominent within the ipsilateral testis.

While damaging both testes, ipsilateral vas deferens obstruction also resulted in increased levels of lactic acid and hypoxanthine in both testes. The mechanism by which contralateral testicular blood flow is affected after unilateral vas deferens obstruction has not been thoroughly evaluated. Decreases in the blood flow of both testes and oxidative stress have been reported after ipsilateral efferent duct ligation [29]. Despite these reports, an autoimmune mechanism has been commonly implicated [30]. Ligation of the vas deferens should increase the pressure within the distal structures and the structure of tunica albuginea may not allow for expansion to decrease the pressure. The increased pressure may therefore decrease the blood flow to the ipsilateral testis through increasing the intratesticular pressure. The increases in the levels of lactic acid and hypoxanthine within the contralateral testis suggest a reflex decrease in contralateral testicular blood flow when the ipsilateral testis is under stress after ligation of the ipsilateral vas deferens.

The mechanisms proposed for contralateral testicular damage in unilateral undescended testis include a preexisting anomaly, lack of testosterone surge at 6090 days of life, auto-immunity and increased oxidative 
stress in both testes after unilateral abdominal testis [29]. A relative hypoxia in the abdominal testis, caused by increased basal metabolism resulting from increased temperature or a decrease in blood flow to the ipsilateral testis and a reflex decrease in contralateral testicular blood when the ipsilateral testis is under stress, has previously been proposed to explain the damage in both testes after the abdominal placement of the ipsilateral testis [23,25]. The abdominal location of the ipsilateral testis for 4 weeks, while confirming ipsilateral and contralateral testicular damage, caused no significant difference among lactic acid and hypoxanthine levels. In a previous experimental model ( 9 weeks of intraabdominal location) there was an increase in both lactic acid and hypoxanthine in both testes [25]. The difference between these studies may have resulted from the different duration of stress, or the absence of any increase in the biochemical indicators of tissue hypoxia may suggest a mechanism other than depressed tissue perfusion.

Evidence of both increased [31] or decreased [8,32] blood flows was reported after varicocele, but in these studies the relative blood flows were evaluated. In the undescended testis, while the relative blood flow is increased, the absolute blood flow is decreased [33]. As the blood flow is inversely proportional to the fourth power of the radius, the flow in a varicose vein should decrease and the measurement of relative flows may not reflect the absolute blood flow. In addition to a significant decrease in testicular blood flow, the energy charge of adenine nucleotides of the varicocele-bearing testes were significantly less than that of the controls [8]. Venous obstruction, previously suggested as an experimental model of varicocele [9], resulted in contralateral testicular damage which could be detected by DNA flow cytometry, but not through histological criteria. Contralateral testicular levels of lactic acid and hypoxanthine, which were also unchanged, may be in accordance with the histological findings. The lesser damage and absence of changes in lactic acid and hypoxanthine level may be explained by the inappropriateness of the model, or inadequate duration.

The present study also confirmed that unilateral testicular torsion, unilateral vas deferens obstruction, unilateral abdominal testis and unilateral venous obstruction not only damage the ipsilateral but also the contralateral testes. As lactic acid and hypoxanthine levels within the contralateral testes were higher than in the controls in groups 2 and 3, they may share a common pathway, which may be the hypoxia arising from the reflex decrease in blood flow. However, the present study cannot explain satisfactorily the mechanism of contralateral damage encountered after ipsilateral abdominal testis and venous obstruction.

\section{References}

1 Krarup T. The testes after torsion. Br J Urol 1978; 50: 43-6

2 Bartsch G, Frank S, Marberger H, Mikuz G. Testicular torsion: late results with special regard to fertility and endocrine function. J Urol 1980; 124: 375-8

3 Tanyel FC, Ayhan A, Büyükpamukçu N, Hiçsönmez A. The fate of testes following unilateral incarcerated inguinal hernia in adult rats. Br J Urol 1989; 64: 176-9

4 Tanyel FC, Ayhan A, Büyükpamukçu N, Hiçsönmez A. Subsequent testicular histology, fertility and fecundity of rats subjected to unilateral incarcerated hernia during prepubertal period. J Pediatr Surg 1991; 26: 204-6

5 Matsuda T, Hiura Y, Muguruma K, Okuno H, Horii Y, Yoshido O. Quantitative analysis of testicular histology in patients with vas deferens obstruction caused by childhood inguinal herniorrhaphy: comparison to vasectomised men. J Urol 1996; 155: 564-7

6 Takihara H, Ishizu K, Ueno T, Isoyama R, Baba Y, Sakatoku J. Pathogenesis of varicocele: experimental study using flow cytometric DNA analysis. Andrologia 1990; 22: 137-43

7 Wang R, Chang JS, Zhou XM, Chen DY. Varicocele in the rat: a new experimental model. Effect on histology, ultrastructure and temperature of the testis and the epididymis. Urol Res 1991; 19: 319-22

8 Hsu HS, Chang LS, Chen MT, Wei YH. Decreased blood flow and defective energy metabolism in the varicocele-bearing testicles of rats. Eur Urol 1994; 25: 71-5

9 Sasagawa I, Tateno T, Yazawa H, Ichiyanagio Nakada T. Assessment of testicular function in experimental varicocele in rats by phosphorus-31 magnetic resonance spectroscopy. Urol Res 1998; 26: 407-10

10 Hagen P, Buchholz M, Eigenmann J, Bandhauer K. Testicular dysplasia causing disturbance of spermogenesis in patients with unilateral torsion of testis. Urol Int 1992; 49: $154-7$

11 Chakraborty J, Hikim APS, Jhujunwala JS. Quantitative evaluation of testicular biopsies from men with unilateral torsion of spermatic cord. Urology 1985; 25: 145-50

12 Madarikan BA. Testicular salvage following spermatic cord torsion. J Pediatr Surg 1987; 22: 231-4

13 Tanyel FC, Büyükpamukçu N, Hiçsönmez A. Contralateral testicular blood flow during unilateral testicular torsion. $\mathrm{Br} \mathrm{J}$ Urol 1989; 63: 522-4

14 Fraser I, Slater N, Tate C, Smart J. Testicular torsion does not cause autoimmunization in man. Br J Surg 1984; 72: $237-8$

15 Hatch D, Alexander N. Immunologic and fertility consequences of spermatic cord torsion: an experimental investigation and review of the literature. J Urol 1986; 135: $190 \mathrm{~A}$

16 Karagüzel G, Gedikoglu G, Tanyel FC, Büyükpamukçu N, Hiçsönmez A. Is ipsilateral testis mandatory for contralateral testicular damage encountered following spermatic cord torsion? Urol Res 1994; 22: 115-7

17 Salman AB, Kilinç K, Tanyel FC. Torsion of only spermatic cord in the absence of testis and/or epididymis results in contralateral testicular hypoxia. Urol Res 1997; 25: $413-5$ 
18 Tanyel FC, Aydin A, Banoglu E, Ipimer A, Büyükpamukçu N. Noradrenaline and nitrite-nitrate concentrations within the contralateral testes during ipsilateral spermatic cord torsion in the presence or absence of testis and epididymis. BJU Int 1999; 83: 833-6

19 Saugstad OD. Hypoxanthine as an indicator of hypoxia: its role in health and disease through free radical production. Pediatr Res 1988; 23: 143-50

20 Kallerhoff M, Gross AJ, Botefur IC et al. The influence of temperature on changes in $\mathrm{pH}$, lactate and morphology during testicular ischaemia. Br J Urol 1996; 78: 440-5

21 Karagüzel G, Tanyel FC, Kilinç K, Büyükpamukçu N, Hiçsönmez A. The preventive role of chemical sympathectomy on contralateral testicular hypoxic parameters encountered during unilateral testicular torsion. Br J Urol 1994; 74: $507-10$

22 Karagüzel G, Gedikoglu G, Tanyel FC, Büyükpamukçu N, Hiçsönmez A. Subsequent biological effects of chemical sympathectomy in rats undergoing unilateral testicular torsion. Eur Urol 1995; 28: 147-51

23 Karnak I, Gedikoglu G, Tanyel FC, Büyükpamukçu N, Hiçsönmez A. The effects of chemical sympathectomy on contralateral testicular histology, fertility and fecundity in unilateral abdominal testis. Br J Urol 1996; 77: 580-4

24 Akgür FM, Kilinç K, Tanyel FC, Büyükpamukçu N, Hiçsönmez A. Ipsilateral and contralateral testicular biochemical acute changes after unilateral testicular torsion and detorsion. Urology 1994; 44: 413-8

25 Karnak I, Tanyel FC, Kilinç K, Büyükpamukçu N, Hiçsönmez A. Tissue hypoxia in ipsilateral and contralateral testes undergoing surgically induced maldescent. Eur J Pediatr Surg 1996; 6: 281-4

26 Salman AB, Mutlu S, Iskit AB, Guc O, Mutlu M, Tanyel FC. Hemodynamic monitorization of contralateral testis during unilateral testicular torsion describes the mechanism of damage. Eur Urol 1998; 33: 576-80

27 Oguzkurt P, Okur DH, Tanyel FC, Büyükpamukçu N, Hiçsönmez A. The effects of vasodilatation and chemical sympathectomy on spermatogenesis after unilateral testi- cular torsion: a flow cytometric DNA analysis. $\mathrm{Br} J$ Urol 1998; 82: 104-8

28 Salman AB, Okur DH, Tanyel FC. DNA flow cytometry reveals depressed spermatogenetic activity in contralateral testis within 24 hours of ipsilateral spermatic cord torsion independent from the presence of the testis and epididymis. Eur Urol 1998; 34: 377-81

29 Zini A, Schlegel PN. Cu/Zn superoxide dismutase, catalase and glutathione peroxidase mRNA expression in the rat testis after surgical cryptorchidism and efferent duct ligation. J Urol 1997; 158: 659-63

30 Tamamato M, Hibi H, Miyake K. The incidence of antisperm antibodies in patients with seminal tract obstructions. Nagoya J Med Sci 1996; 59: 25-9

31 Turner TT, Lopez TJ. Testicular blood flow in peripubertal and older rats with unilateral experimental varicocele and investigation into the mechanism of the bilateral response to the unilateral lesion. J Urol 1990; 144: 1018-21

32 Harrison RM, Lewis RW, Roberts JA. Testicular blood flow and fluid dynamics in monkeys with surgically induced varicoceles. J Androl 1983; 4: 256-60

33 Damber JE, Bergh A, Daehlin L. Testicular blood flow, vascular permeability, and testosterone production after stimulation of unilaterally cryptorchid adult rats with human chorionic gonadotropin. Endocrinology 1985; 117: 1906-13

\section{Authors}

F. Andiran, MD, Paediatric Surgeon. D.H. Okur, PhD, Assistant Professor.

A. Kilinc, MS, Biochemist.

G. Gedikoglug, MD, Associate Professor.

K. Kilinç, PhD, Professor.

F.C. Tanyel, MD, Professor.

Correspondence: Professor Dr F. Cahit Tanyel, Hacettepe University, Faculty of Medicine, Department of Paediatric Surgery, 06100, Ankara, Turkey. e-mail: ctanyel@gen.hun. edu.tr 